\title{
Ignition by Hot Transient Jets in Confined Mixtures of Gaseous Fuels and Air
}

\author{
Abdullah Karimi and M. Razi Nalim \\ Indiana University-Purdue University Indianapolis, Indianapolis, IN 46202, USA \\ Correspondence should be addressed to M. Razi Nalim; mnalim@iupui.edu
}

Received 1 October 2015; Revised 16 February 2016; Accepted 22 February 2016

Academic Editor: Hong G. Im

Copyright (C) 2016 A. Karimi and M. R. Nalim. This is an open access article distributed under the Creative Commons Attribution License, which permits unrestricted use, distribution, and reproduction in any medium, provided the original work is properly cited.

\begin{abstract}
Ignition of a combustible mixture by a transient jet of hot reactive gas is important for safety of mines, prechamber ignition in IC engines, detonation initiation, and novel constant-volume combustors. The present work is a numerical study of the hot jet ignition process in a long constant-volume combustor (CVC) that represents a wave rotor channel. The hot jet of combustion products from a prechamber is injected through a converging nozzle into the main CVC chamber containing a premixed fuel-air mixture. Combustion in a two-dimensional analogue of the CVC chamber is modeled using a global reaction mechanism, a skeletal mechanism, or a detailed reaction mechanism for three hydrocarbon fuels: methane, propane, and ethylene. Turbulence is modeled using the two-equation SST $k-\omega$ model, and each reaction rate is limited by the local turbulent mixing timescale. Hybrid turbulentkinetic schemes using some skeletal reaction mechanisms and detailed mechanisms are good predictors of the experimental data. Shock wave traverse of the reaction zone is seen to significantly increase the overall reaction rate, likely due to compression heating, as well as baroclinic vorticity generation that stirs and mixes reactants and increases flame area. Less easily ignitable methane mixture is found to show slower initial reaction and greater dependence on shock interaction than propane and ethylene.
\end{abstract}

\section{Introduction}

Intentional hot jet ignition of premixed combustible mixture finds application in internal combustion engines $[1,2]$ and pulsed detonation engines [3] and is of particular interest in wave rotor combustors [4-6]. Chemically active radicals and fast turbulent mixing in the jets create an explosion that is more energetic and spatially distributed than a spark [3], allowing rapid ignition of lean and nonuniform mixtures.

Hot jet ignition involves complex flow phenomena, including jet stability, vortex evolution, fluid mixing, and turbulence generation. The presence of reactive species in the jet influences the chemical kinetics of fuel combustion. A highspeed compressible transient jet is usually accompanied by shock formation in a confined volume, leading to subsequent reshaping of flame fronts by shock waves and expansion waves. The ignition delay time for a jet-ignited CVC may be defined as the time from jet initiation to the occurrence of rapid, visible, and pressure-generating heat release in the CVC chamber $[7,8]$. There are many definitions of ignition delay time used in the literature for varied phenomena. Autoignition delay in shock tube and rapid compression experiments depend only on chemical processes, while jet ignition and spark ignition also include physical processes. Ignition delay following hot jet injection includes time for transient jet vortex development, entrainment and mixing with the gas in the CVC chamber, and chemical evolution. In addition, the ignition process in the confined space is influenced by temperature changes due to traveling pressure waves arising from nearby combustion and distant reflection.

A combustible mixture can be ignited by an inert gas jet or reactive gas from another combustion source. Prior experiments mainly addressed mine safety using a steady, relatively low-speed, nonreactive hot gas jet issuing into an unconfined well-mixed stationary or quiescent combustible mixture. In contrast, the hot jet ignition reported here is more similar to turbulent jet ignition systems using prechambers in spark ignition engines, reviewed by Toulson et al. [1]. Such a prechamber mixture is well controlled and reliably spark-ignited and produces a hot jet that acts as a distributed 
ignition source. The jet allows reliable combustion of the main CVC charge over a broader range of air-fuel ratios and more rapid combustion than direct electric spark in lean mixtures. Chemically reactive radicals and jet-induced turbulence are equivalent to two orders of magnitude higher energy than spark ignition [2]. Using various chemically stable hot gases, Wolfhard [9] observed variations in minimum jet temperature for ignition, possibly due to different heat capacities. Vanpée and Wolfhard [10] developed an overall rate expression for ignition of methane and ethane fuel-air mixtures by low-velocity hot inert gas jets. Cato and Kuchta [11] experimented with laminar hot-air jets and concluded that ignition depends on jet base temperature, jet dimensions, composition of the combustible mixture, and jet velocity. Smirnov and Nikitin [12] performed numerical simulation of turbulent diffusive combustion using only three species: oxidant, fuel, and products.

Tarzhanov et al. [13] investigated using hot detonation products to detonate stagnant propane-air mixtures. They found that detonation initiation depends on the initial volume concentrations of the mixture, mass fraction of hot detonation products, and the energy deposited from the detonation products. Using a jet issuing through a circular orifice, Mayinger et al. [14] derived correlations between measured induction time (ignition delay time), the mixing time of the jet, and the adiabatic autoignition time for the fuel-air mixtures.

Bilgin [15] developed a constant-volume combustor (CVC) with long aspect ratio and square cross section, representing a wave rotor channel [16]. The CVC is ignited by a jet of hot combustion products from a separately fueled prechamber that could be spun to cause the jet to traverse one end of the CVC. The relative motion reproduces the action of a wave rotor channel, and prechamber may be representative of a previously combusted channel supplying hot gas. Bilgin proposed a correlation between the Damköhler number and ignition of a fuel-air mixture in the CVC. For the geometry of this CVC, Baronia et al. [17] performed numerical simulations for a stationary (nontraversing) torch jet using global reaction mechanisms (one-step and four-step) for a propaneair mixture. Bilgin's measurements were not well matched by Baronia's simulations, possibly due to lack of detailed chemistry and matched jet composition. Perera [8] carried out experiments on the same CVC test rig for three fuels, methane, ethylene, and propane, with varying equivalence ratios in the prechamber and the CVC chamber. The ignition delay time variation and the ignitability limits, both lean and rich, were investigated for each fuel under fixed initial temperature and pressure conditions in the CVC chamber. The variation of ignition delay time for fuels with different prechamber equivalence ratios and nozzle geometries were also observed, with nonobvious trends.

The ignition of combustible mixture using hot inert jet or combusted products has been rarely studied numerically using global reaction mechanisms, and very few studies that use detailed or skeletal reaction mechanisms are known [18-20]. The present work seeks to use detailed numerical simulations to investigate the ignition by a hot jet and ensuing combustion of three hydrocarbon fuels (methane, propane,

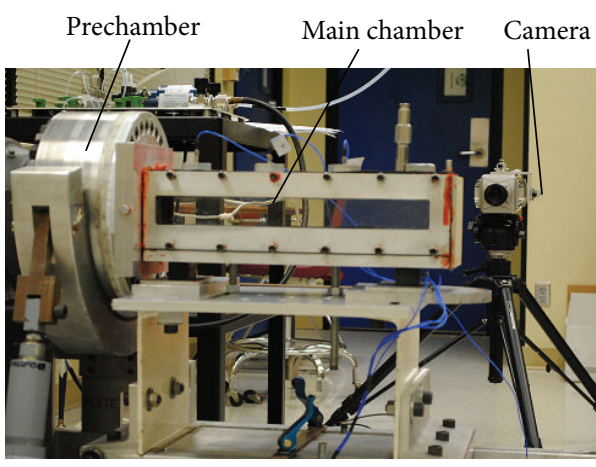

FIGURE 1: Constant-volume combustor rig.

and ethylene). Chemical kinetics are modeled using detailed reaction mechanisms for the three fuels after verifying the inadequacy of a four-step global reaction mechanism for propane. The hot jet is modeled as the equilibrium major products of rich ethylene combustion in the prechamber. The role of shock-flame interaction on ignition in the CVC chamber is also studied. The reaction pathways are discussed for the detailed methane mechanism. The predicted ignition delay times have been compared with the published experimental data [5].

\section{Problem Description and Numerical Methodology}

This work was motivated by the ignition delay studies of Perera et al. [7] in a constant-volume combustor (Figure 1) which is an evolution of the rig initially used by Bilgin et al. [16]. Its main CVC chamber had a square cross section. A converging round nozzle delivers a jet from a cylindrical prechamber to the CVC.

In this work, a simple two-dimensional (2D) combustor, prechamber, and jet nozzle are considered to simulate the transient, turbulent, reacting, and compressible flow at reasonable computational cost. For $2 \mathrm{D}$ calculations to bear some similarity to the experiment of interest, it was decided to preserve the volume ratio of the prechamber to the CVC. This allows the same volume flow rate between the experiment and numerical calculations, preserving mass and energy realism and the nominal pressure history. The height and length of the channel and nozzle are also matched, and the varying width of the nozzle is taken equal to the corresponding diameter. While this does not preserve the area ratio, it does retain the relative height ratio of the confined jet. In the $2 \mathrm{D}$ model, the rectangular CVC is $406.4 \mathrm{~mm}$ (16.0 inches) long and $39.88 \mathrm{~mm}$ (1.57 inches) tall, with nozzle exit width of $5.99 \mathrm{~mm}$ (0.236 inches) centered on end of the CVC. A rectangular prechamber internal cavity has an internal volume of 1.293 times the CVC, not including the small nozzle volume. A leak proof connection between the prechamber and CVC chamber is assumed, as the experiment appears to have negligible gas outflow at low pressure before ignition in the CVC.

The simulation uses the velocity-pressure coupled, second-order implicit scheme available in a general-purpose computational fluid dynamics (CFD) program [25]. 


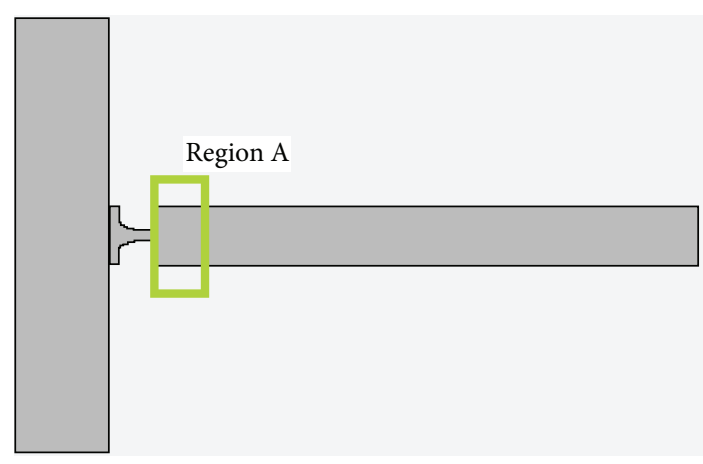

(a) Geometry used for the analysis

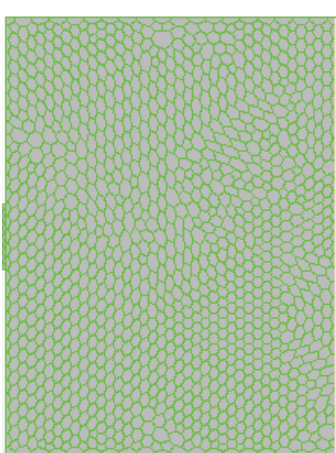

(b) Enlarged view of polyhedral mesh, region $\mathrm{A}$

FIGURE 2: Geometry used for simulation.

TABLE 1: Initial conditions.

\begin{tabular}{|c|c|c|c|c|}
\hline \multirow{2}{*}{ Thermodynamic properties and mass fractions } & \multirow{2}{*}{ Prechamber } & \multicolumn{3}{|c|}{ CVC chamber } \\
\hline & & Methane & Ethylene & Propane \\
\hline Pressure $(\mathrm{kPa})$ & 649 & 101.325 & 101.325 & 101.325 \\
\hline Temperature $(\mathrm{K})$ & 2770 & 298 & 298 & 298 \\
\hline $\mathrm{O}_{2}$ & 0.00691 & 0.219 & 0.217 & 0.218 \\
\hline $\mathrm{N}_{2}$ & 0.719 & 0.725824 & 0.719 & 0.721 \\
\hline $\mathrm{CO}_{2}$ & 0.142 & 0 & 0 & 0 \\
\hline $\mathrm{CO}$ & 0.0504 & 0 & 0 & 0 \\
\hline $\mathrm{H}_{2}$ & 0.000739 & 0 & 0 & 0 \\
\hline $\mathrm{H}_{2} \mathrm{O}$ & 0.0804 & 0 & 0 & 0 \\
\hline $\mathrm{CH}_{4}$ & 0 & 0.0549 & 0 & 0 \\
\hline $\mathrm{C}_{2} \mathrm{H}_{4}$ & 0 & 0 & 0.0634 & 0 \\
\hline $\mathrm{C}_{3} \mathrm{H}_{8}$ & 0 & 0 & 0 & 0.060 \\
\hline
\end{tabular}

Turbulence is modeled using the shear-stress-transport (SST) two-equation $k-\omega$ model [26]. The computational domain is discretized using polyhedral meshes with varying mesh density in the prechamber, nozzle, and CVC chamber (Figure 2). Adiabatic boundary conditions are used for all walls and wall of law is employed for turbulence.

The flow is driven by the initial pressure difference between prechamber and CVC chamber when an intervening diaphragm is suddenly splayed away, similar to a shock tube. Initially, the CVC has a fuel-air mixture at atmospheric pressure and temperature. The prechamber has postcombustion products at a diaphragm rupture pressure measured from experiments [7] and temperature and composition obtained for chemical equilibrium of ethylene-air mixture at an equivalence ratio of 1.1, following Depcik [27], verified with Gordon and McBride [28]. The initial conditions for all simulations are listed in Table 1.

Combustion is modeled using a hybrid eddy-break-up model that considers the roles of both turbulent mixing and finite-rate chemistry. The eddy-break-up (EBU) model was presented by Spalding [29] and later developed by Magnussen and Hjertager [30]. The underlying principle behind the "mixed-is-burnt" EBU model is that the chemistry is fast compared to mixing and the combustion is controlled by turbulent mixing. In the simple EBU model, reaction rates are calculated as functions of the mean species concentrations, turbulent mixing timescale, and, depending on the specific model used, temperature. In the present hybrid EBU model, each individual chemical reaction rate is limited by a maximum rate based on the local turbulent vorticity timescale. Species are transported according to individual advectiondiffusion transport equations for species, with diffusive fluxes accounting for both molecular and turbulent diffusion. It is intended to identify the rate-limiting process as either turbulent mixing or chemical kinetics.

2.1. Reaction Rate. In the hybrid EBU model, the reaction rate of each species is computed as the minimum of a turbulent mixing-controlled reaction rate and chemical kinetic reaction rate. For illustration, a global fuel-oxidation reaction is considered to be of the following form:

$$
v_{F} F+v_{O} \mathrm{O} \longrightarrow v_{P 1} P_{1}+v_{P 2} P_{2}+\cdots+v_{P j} P_{j}
$$

The molar rate of fuel depletion $R_{F, \text { mix }}$ based on the turbulent micromixing process depends on the mass fractions of 
reactant and product species and the turbulent mixing rate, which is taken to be the turbulent specific dissipation, $\omega$ :

$$
\begin{aligned}
R_{F, \text { mix }} & =\frac{\rho}{M_{F}} \omega A_{\mathrm{EBU}} \\
\cdot \min & {\left[\overline{Y_{F}}, \frac{\overline{Y_{O}}}{s_{O}}, B_{\mathrm{EBU}}\left(\frac{\overline{Y_{P 1}}}{s_{P 1}}+\frac{\overline{Y_{P 2}}}{s_{P 2}}+\cdots+\frac{\overline{Y_{P j}}}{s_{P j}}\right)\right] \text { moles } / \mathrm{m}^{3} \text {-s. } }
\end{aligned}
$$

Equation (2) states that the overall reaction requires both reactants and products to be present in proportion to their mass stoichiometric coefficients, given by

$$
\begin{gathered}
s_{O}=\frac{v_{O} M_{O}}{v_{F} M_{F}}, \\
s_{P i}=\frac{\left|v_{P i}\right| M_{O}}{v_{F} M_{F}} .
\end{gathered}
$$

The products have lower weighting, with the values of $A_{\mathrm{EBU}}$ and $B_{\mathrm{EBU}}$ being kept at the nominal values of 4.0 and 0.5 , respectively, for all the reactions [30]. When a detailed mechanism or any multistep reaction mechanism is used, the EBU model is applied to each of the reactions. For each reaction rate, a turbulence-limited reaction rate $R_{j, \text { mix }}$ is calculated based on its own reactants and products.

The reaction rate for reaction $j$ predicted from finite-rate chemistry is obtained using modified Arrhenius form, using the detailed chemical mechanism selected for a particular fuel:

$$
R_{j, \text { kin }}=-A_{j} T^{B_{j}} \prod_{\text {all reactants }}\left(\frac{\rho Y_{i}}{M_{i}}\right)^{p_{i j}} e^{-E_{a j} / R T}
$$

In the species transport equations, the reaction source term for each species is

$$
S_{i}=M_{i} \sum_{j=1}^{n_{R}} v_{i j} R_{j}
$$

where the actual reaction rate is the minimum of the reaction rates from the Arrhenius kinetic rate of (4) and the turbulence-mixing rate of (2). This can be expressed mathematically as

$$
R_{j}=-\min \left(\left|R_{j, \mathrm{kin}}\right|,\left|R_{j, \mathrm{mix}}\right|\right) .
$$

One-step global reaction mechanisms validated for a particular flame propagation phenomenon, such as a laminar flame, are generally not applicable to ignition phenomena. The hot jet ignition process in the CVC is a complex transient reaction-mixing-diffusion problem that requires detailed modeling of chemistry. Nevertheless, some multistep reaction mechanisms, skeletal mechanisms, and reduced mechanisms may be adequate for estimating ignition delay and justifiable relative to the computational cost of a detailed mechanism. Table 2 is a list of the reaction mechanisms used in the present study for the three fuels. Reduced mechanisms include algebraic equations for minor species concentrations assumed to be in the steady state, which must then be added to the main time-integration computation.
TABLE 2: Reaction mechanisms.

\begin{tabular}{lccc}
\hline Fuel & Mechanism reference & $\begin{array}{c}\text { Number of } \\
\text { reactions }\end{array}$ & $\begin{array}{c}\text { Number of } \\
\text { species }\end{array}$ \\
\hline Methane & GRI-Mech 3.0 [21] & 325 & 53 \\
& DRM19 [22] & 84 & 21 \\
\hline Ethylene & Luo et al. 2012 [23] & 206 & 32 \\
\hline Propane & UCSD [24] & 173 & 40 \\
\hline
\end{tabular}

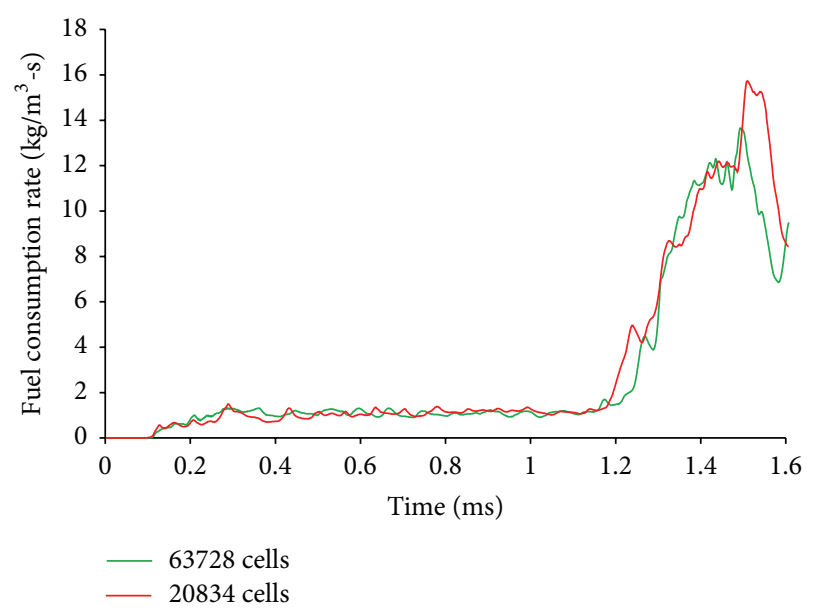

FIGURE 3: Fuel consumption rate integrated over the CVC chamber for the two grids for methane mixture using DRM19 reaction mechanism.

2.2. Grid Sensitivity. A grid-sensitivity study is presented considering a methane-air mixture in the CVC chamber and using a 21-species reaction mechanism, DRM19, in the hybrid approach described above. Two different grid sizes were used for the CVC chamber with minimum cell sizes of $1.0 \mathrm{~mm}(20,834$ total cells $)$ and $0.5 \mathrm{~mm}(63,728$ total cells). The fuel consumption rates predicted with the two grids were found to differ slightly and only after ignition occurs, as presented in Figure 3. Although details of the jet structure and flame propagation have visible differences, the two grids also show similar history of jet penetration and flame position (Figure 4). The critical feature of ignition delay time as characterized by the rapid acceleration of fuel consumption rate beginning at about $1.2 \mathrm{~ms}$ from the start is not significantly different between the two grids. Therefore, it is deemed that the variations are acceptable relative to the variability observed in experiments, and the grid with minimum cell size of $1.0 \mathrm{~mm}$ in the CVC chamber is used henceforth. It should be noted that the present study is not intended to resolve the flame thickness or to estimate flame speed after ignition. The mesh used here is intended to predict the ignition delay time influenced by mixing in relatively large-scale jet vortex structures but may not be adequate for predicting subsequent flame propagation controlled by relatively smaller turbulence scales.

\section{Mechanisms and Ignition Delay Predictions}

The prediction of ignition behavior using appropriate chemical kinetic mechanisms is a limited goal of this work. It is 

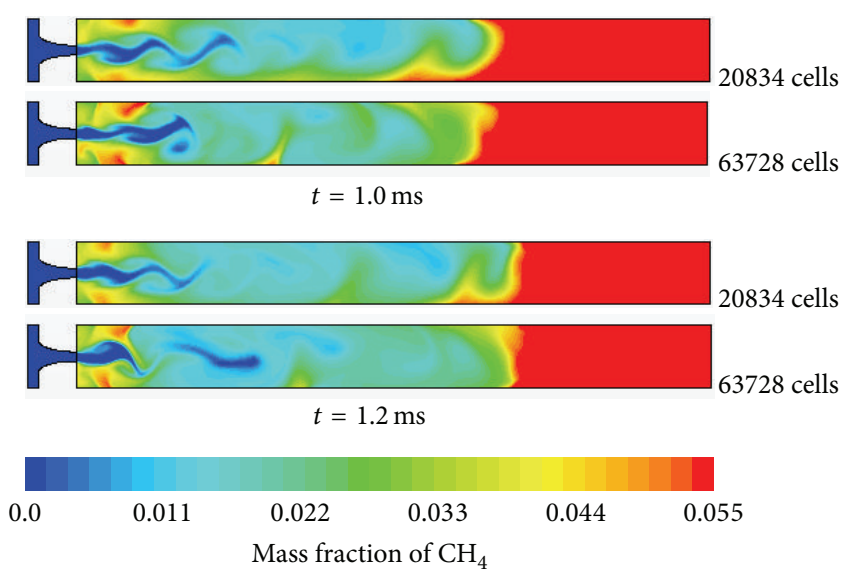

Figure 4: Methane mass fraction levels for two different grids for methane mixture in the CVC chamber using DRM19 reaction mechanism.

intended to elucidate the major determinants of ignition and combustion acceleration, as a first step towards a definition and measurement of ignition delay time for a transient jet.

3.1. Types of Reaction Mechanisms. Single-step mechanisms, few-step global reaction mechanisms, and quasi-global mechanisms that oversimplify key initiation steps are generally not validated for ignition delay prediction, and their application for hot jet ignition study will be of limited usefulness. With this caution in mind, a 4-step global reaction mechanism for propane that is reported to be validated for ignition delay in flow reactors and shock tubes [31] was evaluated early in the present study. Using the modeling approach for the CVC hot jet ignition system described above, the reactive flow in the combustion chamber was simulated using the four-step reaction mechanism and a detailed propane combustion mechanism [24]. The history of total reaction rate of fuel in the CVC chamber predicted by the two mechanisms (Figure 5) differs significantly, qualitatively, and quantitatively in the first $3 \mathrm{~ms}$ considered. Single-step and few-step global mechanisms have implied representations of flame species diffusion and intermediate species chemistry that generally do not apply to jet ignition. Moreover, autoignition effects during shock-flame interaction require detailed representation of initiation reactions. Henceforth, detailed or skeletal reaction kinetic mechanisms are used for the further detailed investigation presented here.

3.2. Ignition Chemistry for Methane. The detailed reaction mechanism used in the present work for methane is GRIMech 3.0 [21]. Incorporating the well-studied and unusual reaction pathways and autoignition timescale of methane, it involves 53 species among 325 elementary reactions. For lower computational expense, a skeletal mechanism of 21 species, DRM19 [22], derived from GRI-Mech 3.0 is also used. A review of DRM19 is given by Mardani et al. [32]. The average fuel consumption rate in the CVC chamber predicted by GRI-Mech 3.0 and DRM19 is presented in Figure 6. It is noted that, with either mechanism for methane, the reaction

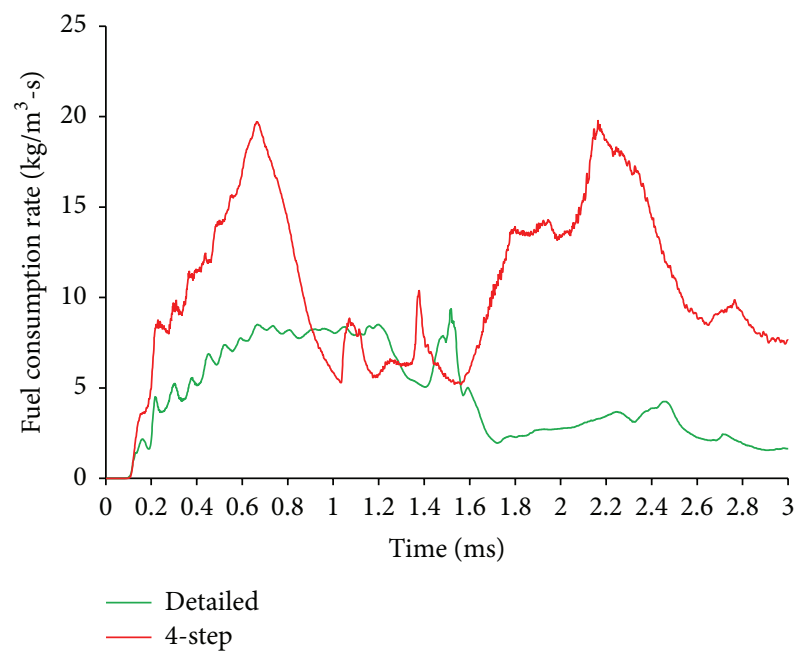

FIGURE 5: CVC chamber-integrated fuel consumption rate for propane-air mixture, predicted using 4-step global reaction mechanism and detailed reaction mechanism.

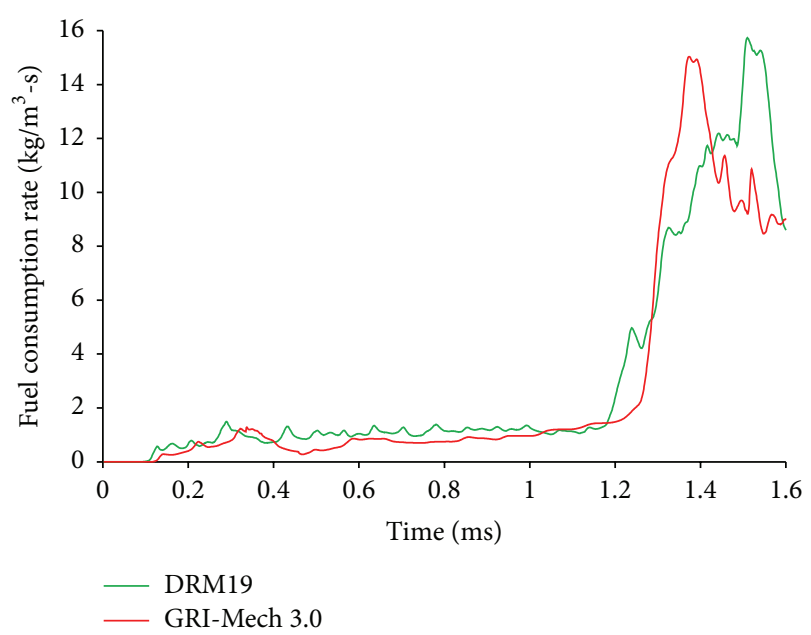

FIGURE 6: CVC chamber-integrated reaction rate for methane-air mixture, predicted using GRI-Mech 3.0 and DRM19.

rates are relatively small until the shock-flame interaction at about $t=1.2 \mathrm{~ms}$. The two mechanisms are in good agreement on the peak value of fuel consumption rate but show important differences. Examination of the history of $\mathrm{CH}_{3}$, an important intermediate species, showed that DRM19 overpredicts the $\mathrm{CH}_{3}$ concentration beyond $t=1.3 \mathrm{~ms}$, but the timing of peak $\mathrm{CH}_{3}$ corresponds closely with peak fuel consumption with either mechanism. Considering the computation cost savings and typical variations observed in experiments [8], predictions using DRM19 are deemed adequate and are the basis of discussion henceforth.

3.3. Kinetic Mechanisms for Ethylene and Propane. The skeletal reaction mechanism used for ethylene involves 32 species in 206 reversible elementary reactions [23] and is derived from the USC Mech-II detailed mechanism [33]. For propane, the detailed reaction mechanism from the University 


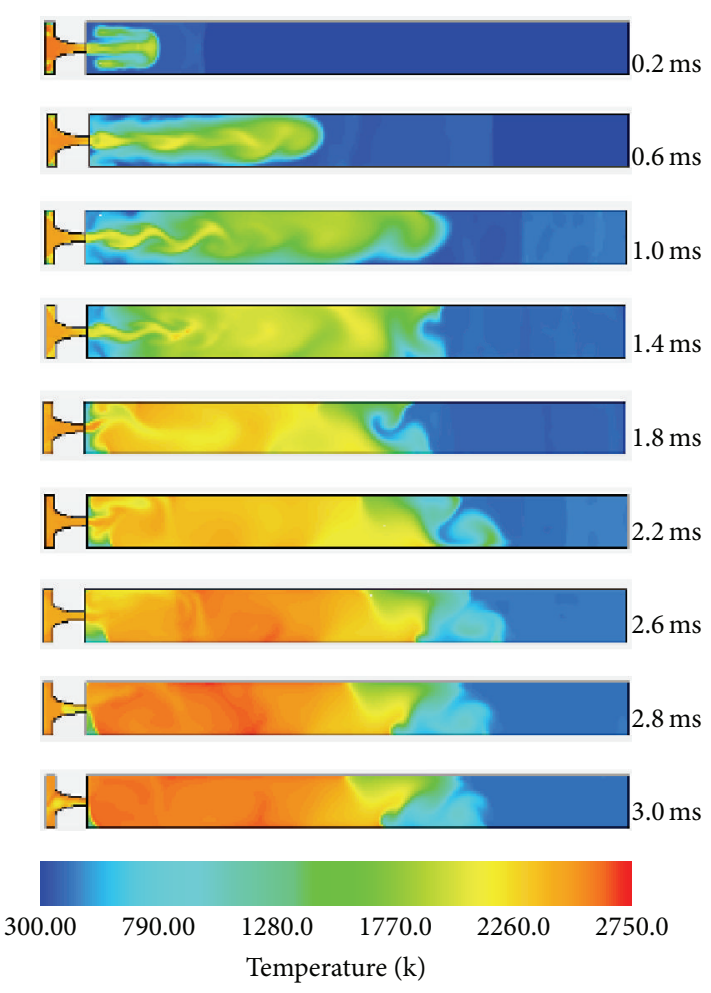

(a)
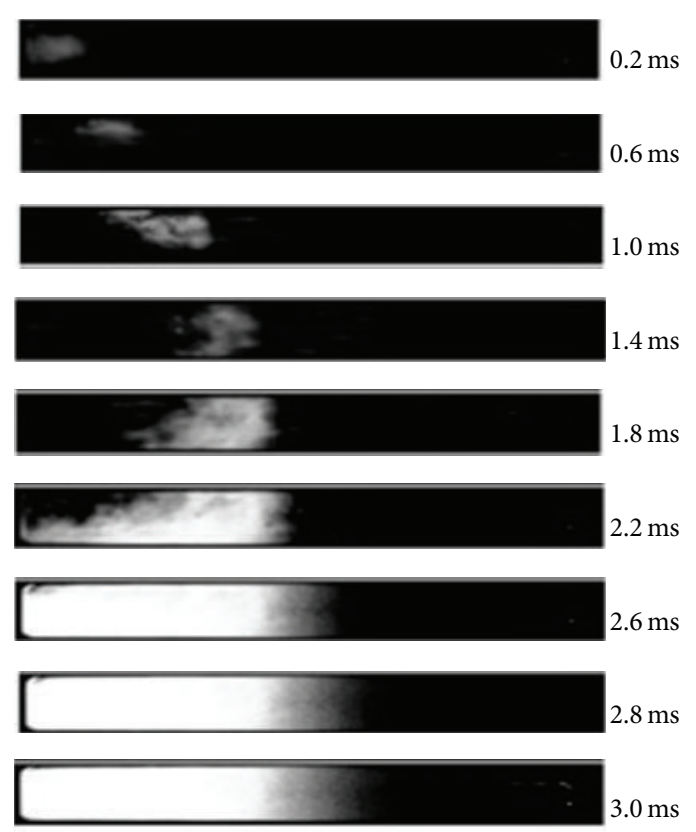

(b)

FIGURE 7: Combustion progress for stoichiometric methane mixture in the CVC chamber. (a) Temperature levels from simulations. (b) Flame luminosity in high-speed video images [8].

of California, San Diego, is used, which involves 40 species [21]. The reaction rates for different fuels are compared and discussed further in later sections.

3.4. Ignition Delay. The ignition delay for room-temperature CVC fuel-air mixtures using methane, ethylene, and propane will be discussed in this section. While there are many definitions of ignition delay time for different modes of ignition, the estimation of ignition delay time generally requires interpretation of the evidence for accelerating reaction. For shock-initiated ignition of premixed gas, Davidson and Hanson [34] reported that pressure is a good indicator of ignition at high fuel concentrations. They also found that $\mathrm{CH}^{*}$ and $\mathrm{OH}$ (and intermediate species $\mathrm{C}_{3} \mathrm{H}_{6}$ ) mole fraction histories show clear evidence of a change owing to ignition. In hot jet ignition, where the chemically active hot gas mixes with the cold combustible mixture, the definition of ignition delay must ideally consider all steps from the mixing process to the release of substantial fuel energy. With this caveat, the ignition event could reasonably be defined as occurring either at the time of maximum rate of change or at the time when the peak value of some species or variable such as $[\mathrm{OH}],[\mathrm{CH}]$, or pressure is reached. Alternatively, it could be based on an extrapolation of the maximum slope to the zero signal level.

A goal of this work is to understand the main features of ignition observed in experiments. High-speed video images of the experiments [8] are presented in Figure 7 for the methane mixture. Despite geometry differences, there is some qualitative similarity in stages of the jet, its penetration, and regions of high flame (soot) luminosity when compared alongside with predicted flame temperatures over about $2000 \mathrm{~K}$. In particular, despite jet penetration and mixing, there is significant reaction progress; that is, ignition does not occur in both experiment and simulation until the arrival of the first reflected shock at about $t=1.2 \mathrm{~ms}$. In contrast with methane, experiments [7] using propane and ethylene show relatively little influence of any specific shock wave interaction. A comparison of the predicted spatial and temporal fuel concentration for methane and ethylene (Figure 8) supports this experimental observation. Despite remarkable similarity of jet development and even of the shape evolution of the leading edge of fuel consumption front, the timing of substantial fuel consumption is very different (Figure 9(a)).

These observations must be interpreted carefully, considering the spatial distribution of fuel over time, the expected chemical kinetics in a mixture which is initially at room temperature, and the limitations of the computational method. During the computed time period, high rates of fuel consumption occur in a spatially broad region of CVC mixture entrained in the jet, for both ethylene and methane, though at later times for methane. Even the postshock increase in reaction rate of methane is primarily associated with the temperature and concentration changes of the partially mixed gas region, due to bulk stirring driven baroclinic vorticity deposited in the region and by shock compression heating. Mainly transverse temperature gradients (Figure 7(a)) before 


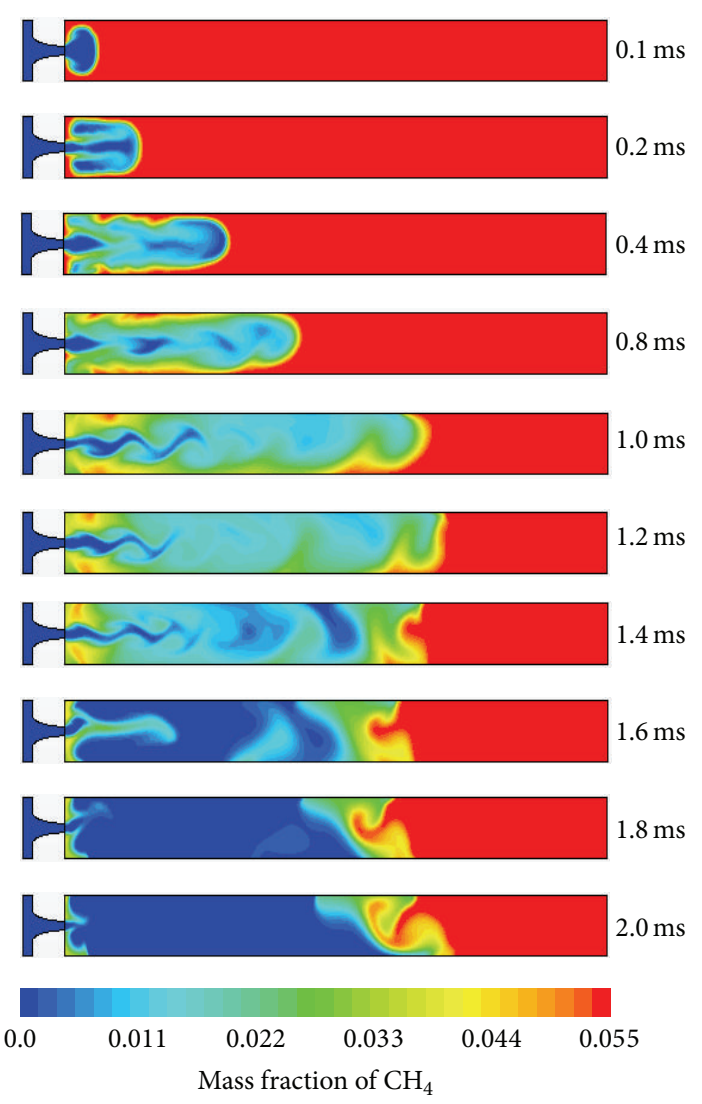

(a)

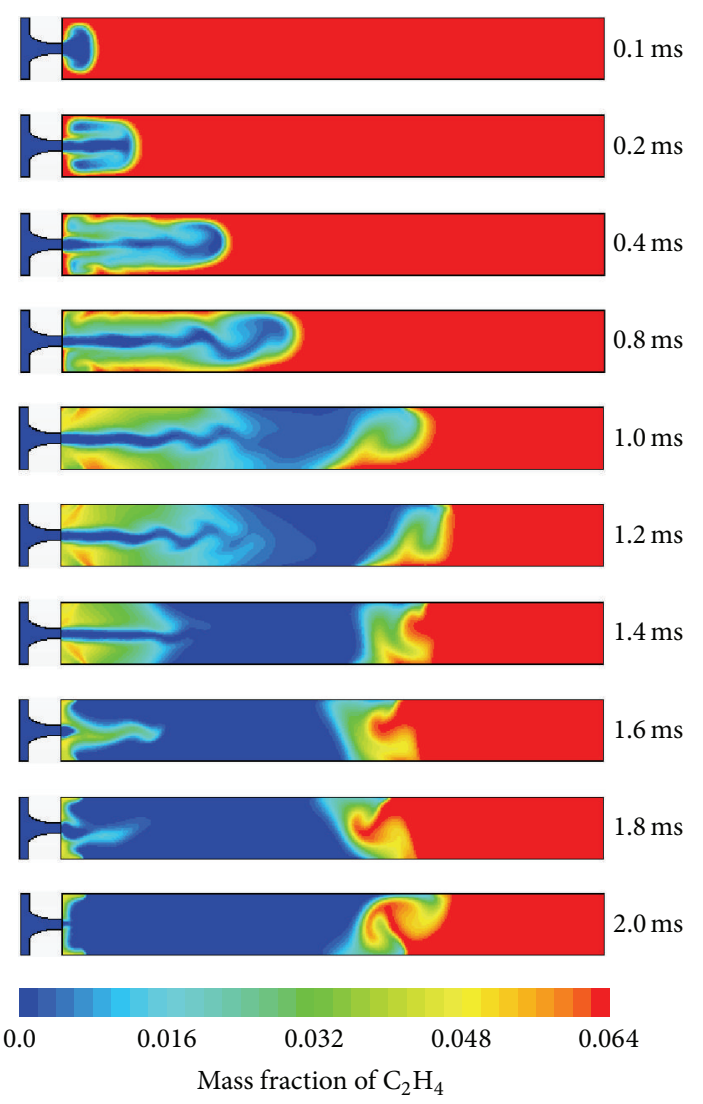

(b)

FIGURE 8: Fuel mass fraction: (a) methane-air combustion predicted using DRM19 (21 species) reaction mechanism; (b) ethylene-air combustion predicted using detailed reaction mechanism (32 species).

shock arrival are later smeared away. The shock interaction with the density gradient at the leading edge of this region is dramatic but probably secondary for fuel consumption until a "flame" exists there.

The computed fuel and oxygen consumption rates for methane, ethylene, and propane integrated over the CVC chamber are revealing. In Figure 9(a), the consumption rate of fuel mass over time confirms the slower kinetics of methane relative to other fuels. For methane, consumption accelerates rapidly after shock arrival at the reacting region at $1.2 \mathrm{~ms}$. This is attributed to the temperature increase by compression of the interior bulk of this region and smaller-scale mixing and homogenization due to baroclinic vorticity deposition within this region. For ethylene and propane, at the same initial temperatures, the fuel consumption occurs rather steadily from the time the hot jet enters the CVC chamber $(t=0.2 \mathrm{~ms})$, and no sharp increase is seen upon shock compression. However, in Figure 9(b), it is seen that oxygen consumption rate in the CVC chamber undergoes rapid increase at shock compression for all three fuels. This reflects oxidation of intermediate hydrocarbon species that had already been created from ethylene and propane, while for methane it is primarily the initial oxidation of the fuel. Thus the shock does influence the heat release phase of reaction for all three fuels, but it is decisive in initiating the reaction of methane.
Experiments with hot jet ignition $[7,8]$ using high-speed video images tend to support this interpretation, in that hot soot incandescence appears to occur only after shock arrival for all three fuels.

The chamber-integrated histories of some intermediate species are shown for methane, propane, and ethylene fuels in Figure 10. Comparing the histories of intermediate species concentration in the CVC chamber for different fuels, it is seen that $C_{1}$ and $C_{2}$ species history exhibits slower ignition activity for methane when compared with ethylene and propane. The history of $\mathrm{OH}, \mathrm{H}$, and $\mathrm{HO}_{2}$ shows similar trends for all three fuels. In the next section, we use detailed maps of the distribution of some species to explain the above trends from the reaction pathways for conversion of a fuel mixture into final products $\mathrm{CO}_{2}$ and $\mathrm{H}_{2} \mathrm{O}$.

Examining methane combustion in more detail, the history of molar concentration of important intermediate species in the CVC chamber is presented in Figures 10(a) and 10(b). The $\mathrm{CH}_{3}$ concentration appears to be a useful indicator for ignition delay time quantification; it is seen in Figure 10(a) that a rapid increase of $\mathrm{CH}_{3}$ occurs between $t=$ $1.2 \mathrm{~ms}$ and $t=1.5 \mathrm{~ms}$. Observing the molar concentration histories of $\mathrm{OH}, \mathrm{H}$, and $\mathrm{HO}_{2}$ (Figure 10(b)), it appears that the production of these species peaks near $2.5-3 \mathrm{~ms}$, which is about a millisecond later than when the hydrocarbon 


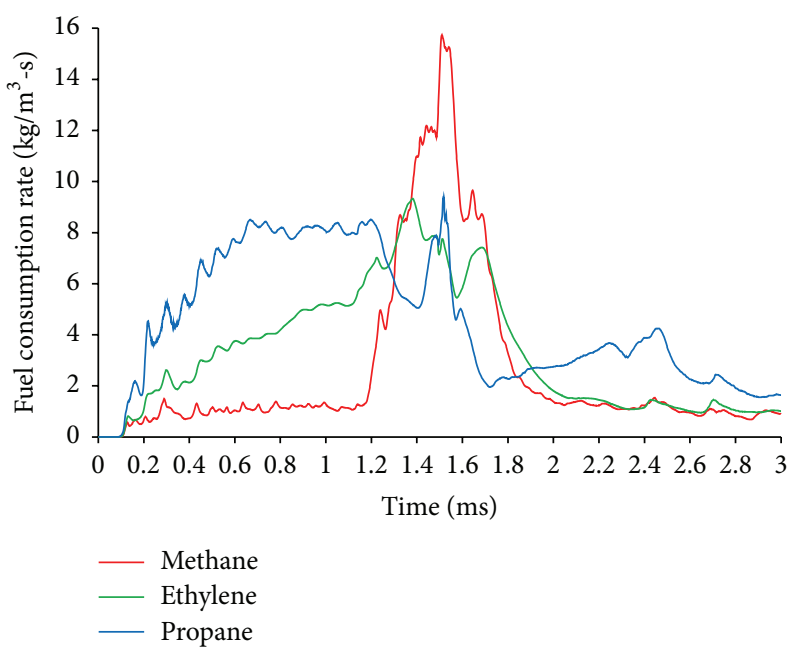

(a) CVC chamber-integrated fuel consumption rate

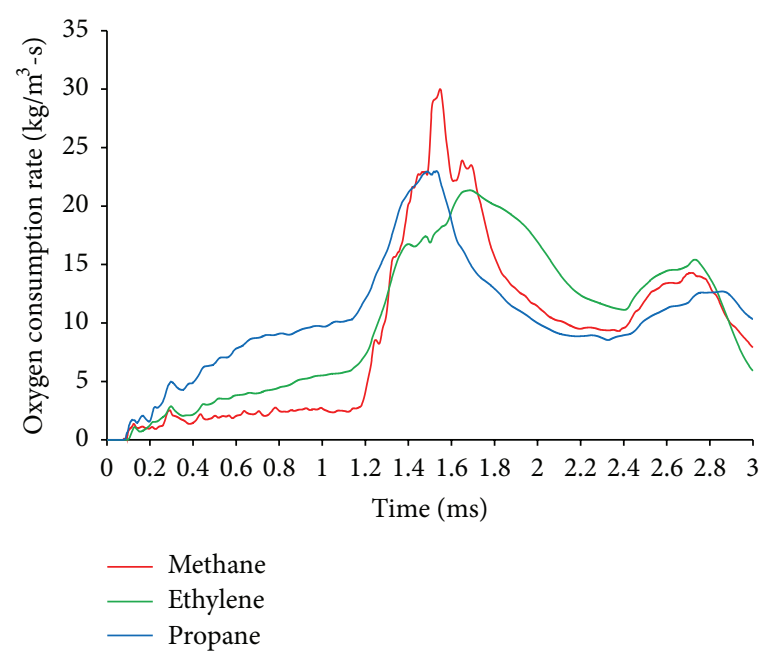

(b) CVC chamber-integrated oxygen consumption rate

FIGURE 9: Comparison of fuel and oxygen reaction rates in the CVC chamber for three fuel mixtures, integrated over the chamber volume.

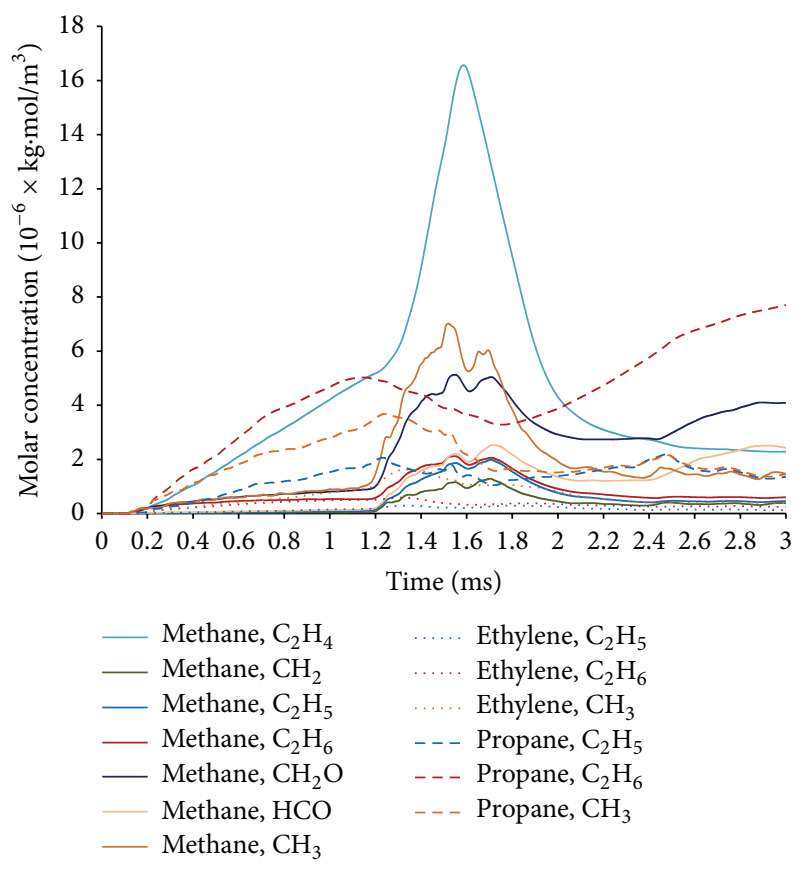

(a)

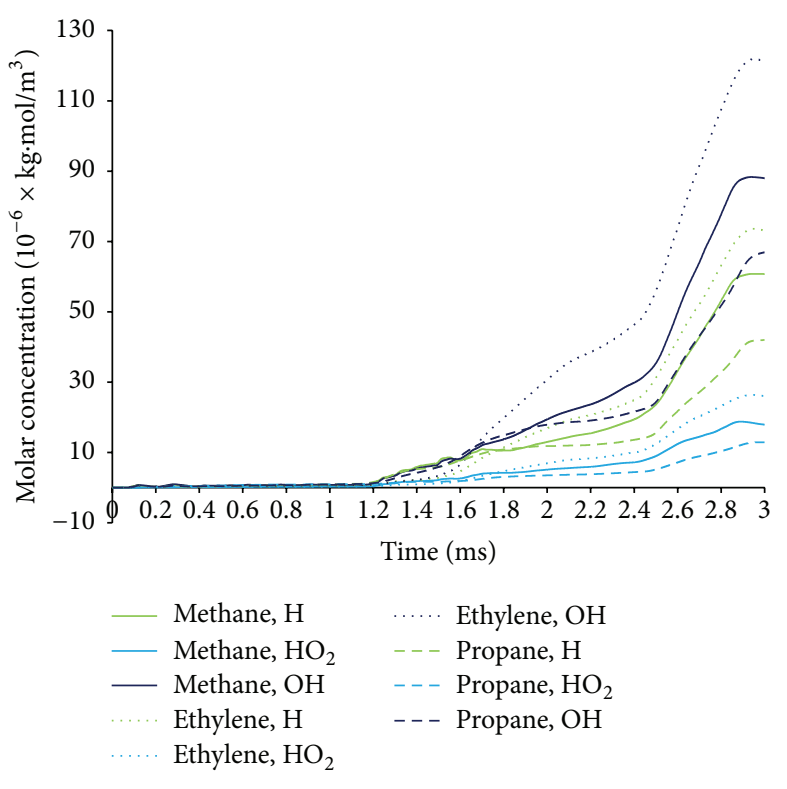

(b)

FIGURE 10: CVC chamber-averaged molar concentrations of intermediate species for different fuel-air mixtures.

intermediate with one or two carbon atoms $\left(\mathrm{C}_{1}\right.$ and $\left.\mathrm{C}_{2}\right)$ species shows peaks. To understand these trends better, the distribution of representative species is examined. In Figure 11, it is observed that the small hydrocarbon species $\mathrm{CH}_{3}$ is concentrated in the "flame" at the boundary between the jet mixing region and the unburned region, and similar distribution is observed for $\mathrm{CH}_{2} \mathrm{O}$ and $\mathrm{HCO}$. On the other hand, $\mathrm{CO}$ (Figure 12) persists in the jet mixing region for a brief time and is always present in the flame. In contrast, $\mathrm{OH}$ (Figure 13) and $\mathrm{H}$ are formed and persist for a relatively longer period throughout the jet mixing region; thus the quantities of $\mathrm{H}$ and $\mathrm{OH}$ are overall greater than the minor $\mathrm{C}$ species.

These observations point to the need for studying the chemical activity in the mixed region and in the boundary region separately, as both can be important for ignition and combustion activity in the chamber. In particular, the arrival of the shock wave triggers the formation of $\mathrm{H}, \mathrm{OH}$, and $\mathrm{HO}_{2}$ in the bulk of the mixing region for all three fuels. Thus, even in the case of ethylene and propane, where there is quicker initial reaction of the fuel molecule within the mixing region, 


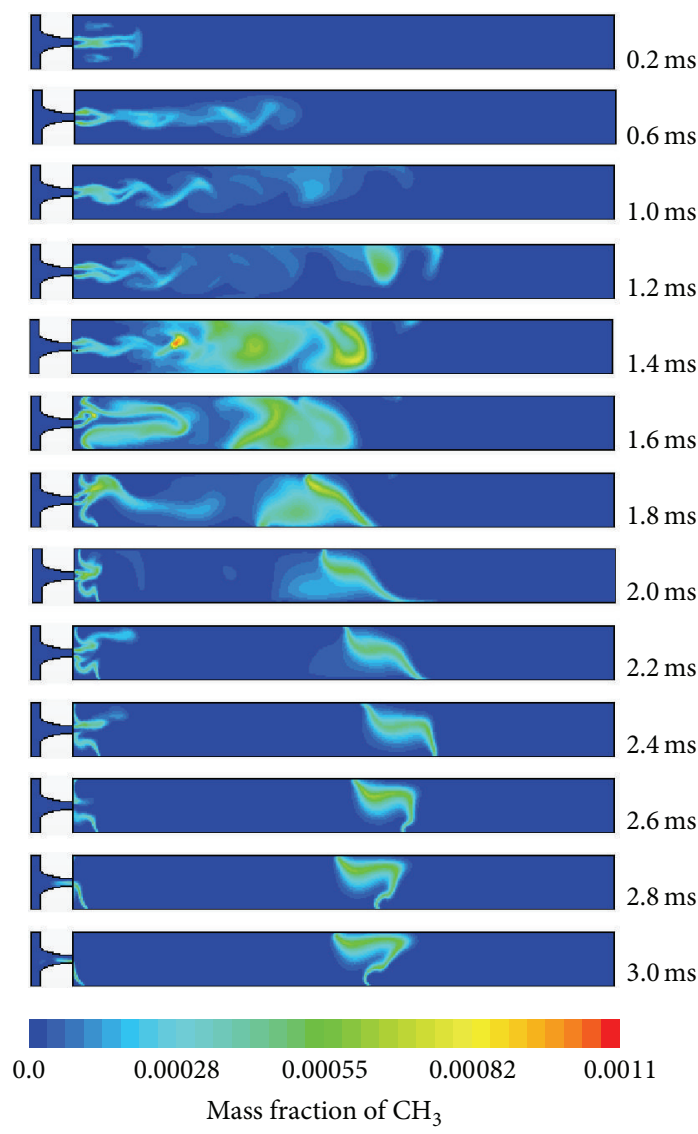

FIGURE 11: $\mathrm{CH}_{3}$ mass fraction during methane-air combustion predicted using DRM19 mechanism.

the formation of $\mathrm{H}, \mathrm{OH}$, and $\mathrm{HO}_{2}$ is significant only after shock arrival.

3.5. Reaction Pathways. In this section, reaction pathways are discussed for methane, ethylene, and propane combustion. For methane fuel, the temperature predicted in the CVC chamber mixed region, before ignition occurs at about $1.2 \mathrm{~ms}$, is found to be in the range of $1600-1800 \mathrm{~K}$. The reaction pathways for the combustion of methane are dependent on the initial composition and temperature. The jet composed of combustion products entrains fuel and air into vortical structures that may be treated as stirred reactors. In wellstirred reactors at high temperature $(>2000 \mathrm{~K})$, the main pathway for $\mathrm{CH}_{4}$ combustion is $[35,36]$

$$
\mathrm{CH}_{4} \longrightarrow \mathrm{CH}_{3} \longrightarrow \mathrm{CH}_{2} \mathrm{O} \longrightarrow \mathrm{HCO} \longrightarrow \mathrm{CO} \longrightarrow \mathrm{CO}_{2}
$$

At low temperature $(<1500 \mathrm{~K})$, an additional reaction pathway of methane combustion is [33]

$$
\begin{aligned}
\mathrm{C}_{2} \mathrm{H}_{6} & \longrightarrow \mathrm{C}_{2} \mathrm{H}_{5} \longrightarrow \mathrm{C}_{2} \mathrm{H}_{4} \longrightarrow \mathrm{C}_{2} \mathrm{H}_{3} \longrightarrow \mathrm{C}_{2} \mathrm{H}_{2} \\
& \longrightarrow \mathrm{CO}, \mathrm{CH}_{2}
\end{aligned}
$$

The reaction mechanism used in this work for methane, DRM19, does not include $\mathrm{C}_{2} \mathrm{H}_{3}$ and $\mathrm{C}_{2} \mathrm{H}_{2}$. It does include $\mathrm{C}_{2} \mathrm{H}_{6}, \mathrm{C}_{2} \mathrm{H}_{5}$, and $\mathrm{C}_{2} \mathrm{H}_{4}$, and these may be used to infer the

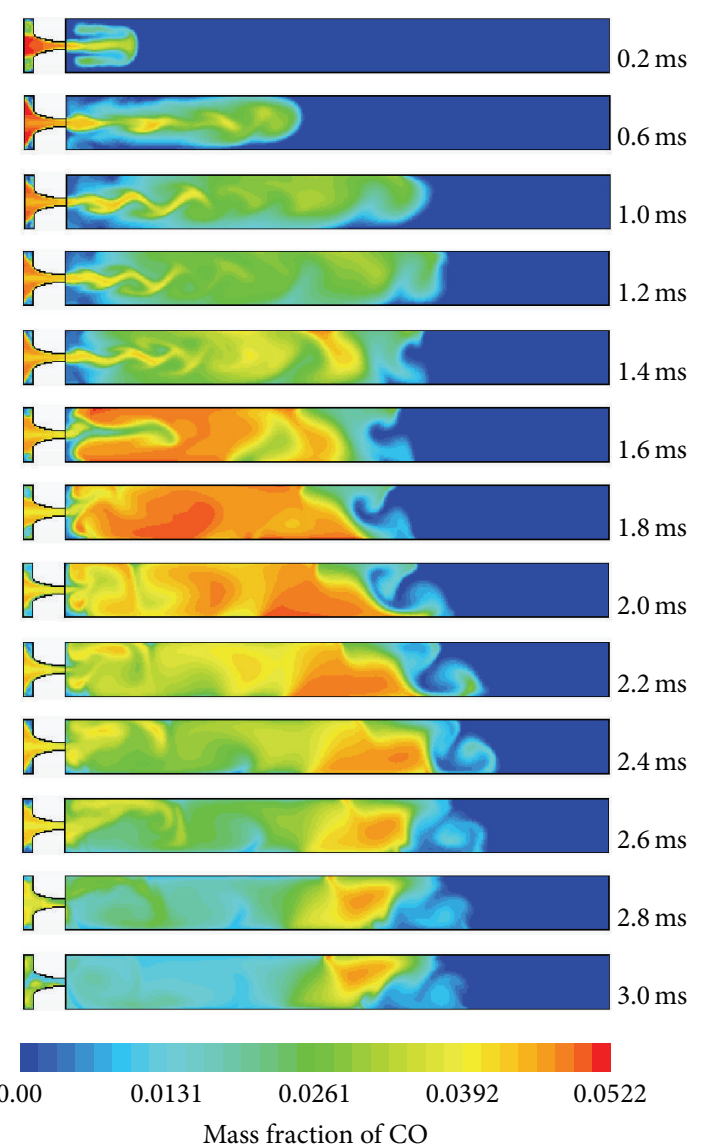

FIgURE 12: CO mass fraction during methane-air combustion predicted using DRM19 mechanism.

importance of the low-temperature pathway. From Figures 10(a) and 10(b), it is observed that the relative stability of $\mathrm{C}_{2} \mathrm{H}_{4}$ appears to limit rapid fuel consumption until reflected shock interaction about $1.2 \mathrm{~ms}$. $\mathrm{CH}_{2}, \mathrm{CH}_{3}, \mathrm{CH}_{2} \mathrm{O}$, and other higher hydrocarbons attain their maximum molar concentrations between $1.5 \mathrm{~ms}$ and $1.7 \mathrm{~ms}$ and then decrease through the oxidation of these species into $\mathrm{CO}$ and eventually into $\mathrm{CO}_{2}$ at about $3.0 \mathrm{~ms}$, as seen later. It is noted that there is again a slight increase in $\mathrm{CH}_{2} \mathrm{O}$ and $\mathrm{HCO}$ around 2.6-3.0 ms. This is consistent with the above mechanisms and with examination of the distribution of these two species (not shown here). The molar concentration of $\mathrm{H}, \mathrm{OH}$, and $\mathrm{HO}_{2}$ is observed to increase from about $1.2 \mathrm{~ms}$ to about $2.9 \mathrm{~ms}$.

The appearance of hydrocarbon molecules larger than the initial reactant hydrocarbon is a feature of low-temperature oxidation [35]. The relative levels of $\mathrm{C}_{2} \mathrm{H}_{4}$ and other $\mathrm{C}_{2}$ species (Figure 10) indicate that the low-temperature reactions pathways may be active in the CVC jet ignition. It can be thus inferred that the two reaction pathways described above are probably both important. It can be observed from Figure 10 (a) that the intermediate species $\mathrm{C}_{2} \mathrm{H}_{4}$ continuously increases from the time the hot jet enters the $\mathrm{CVC}$ chamber. This behavior is very different from other $C_{1} / C_{2}$ species for methane combustion.

The level plots of $\mathrm{CH}_{3}, \mathrm{OH}$, and $\mathrm{CO}$ in Figures 11-13 allow deeper understanding of the processes in the mixed 


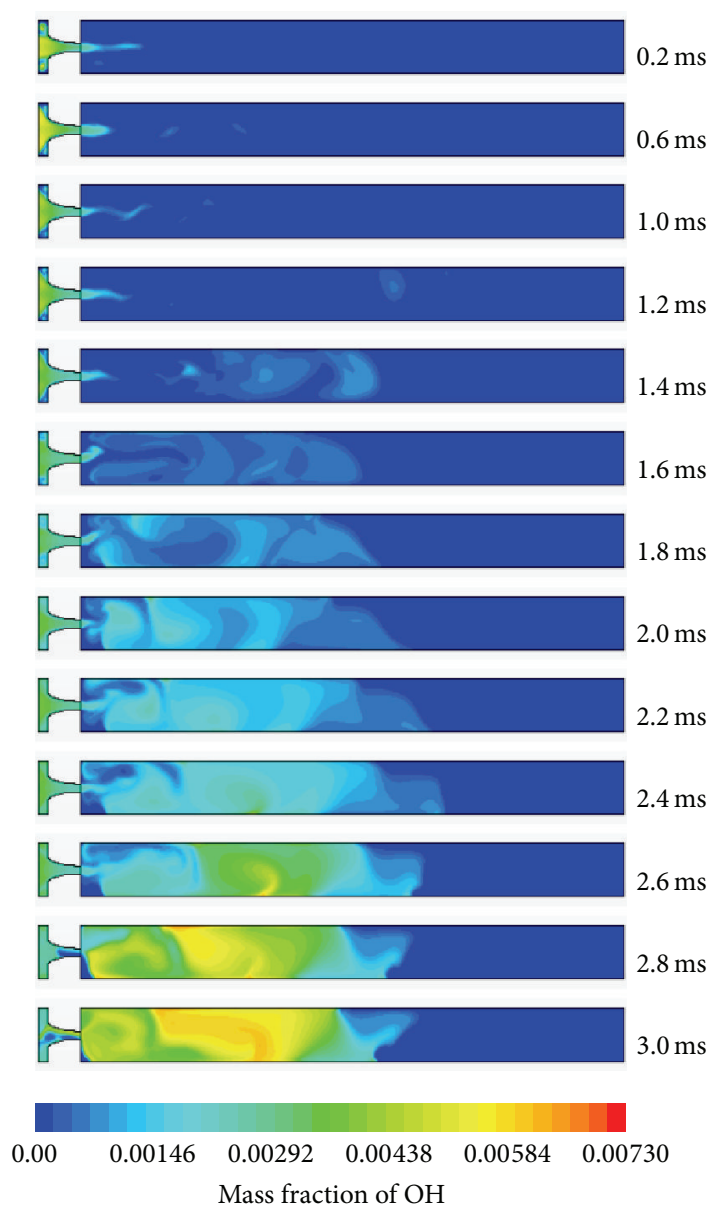

FIGURE 13: $\mathrm{OH}$ mass fraction during methane-air combustion predicted using DRM19 mechanism.

region near the jet and the boundary between the mixed region and unburned region. The distribution of $\mathrm{CH}_{3}$ in Figure 11 shows concentrations in the mixing region initially, with rapid formation in several localized areas when the first shock compresses the mixed region at $1.2-1.3 \mathrm{~ms}$. After about $2 \mathrm{~ms} \mathrm{CH}_{3}$ is concentrated at the boundary flame between the mixed and unburned regions. The $\mathrm{CH}_{3}$ concentration within the flame is observed to increase again when the next shock reflection arrives from the unburned region at about $2.6 \mathrm{~ms}$. This is expected as the freshly burning fuel produces $\mathrm{CH}_{3}$ and it is quickly consumed; the enhanced mixing and compression heating by the shock increases the rate of fuel consumption locally, producing $\mathrm{CH}_{3}$.

In contrast with the minor hydrocarbon intermediates, the distribution of $\mathrm{OH}$ and $\mathrm{CO}$ is more uniform and persistent throughout the jet mixing region. The $\mathrm{OH}$ concentration (Figures 10 and 13) grows slowly within the mixing region, intensifying with the multiple shock interactions, throughout the simulation period until $3.0 \mathrm{~ms}$. The CO concentration (Figure 12) also grows throughout the mixing region, reaching highest levels around $1.6-1.8 \mathrm{~ms}$ and then falling with oxidation to $\mathrm{CO}_{2}$.

These observations point to the need for carefully modeling the ignition process by considering the mixing and

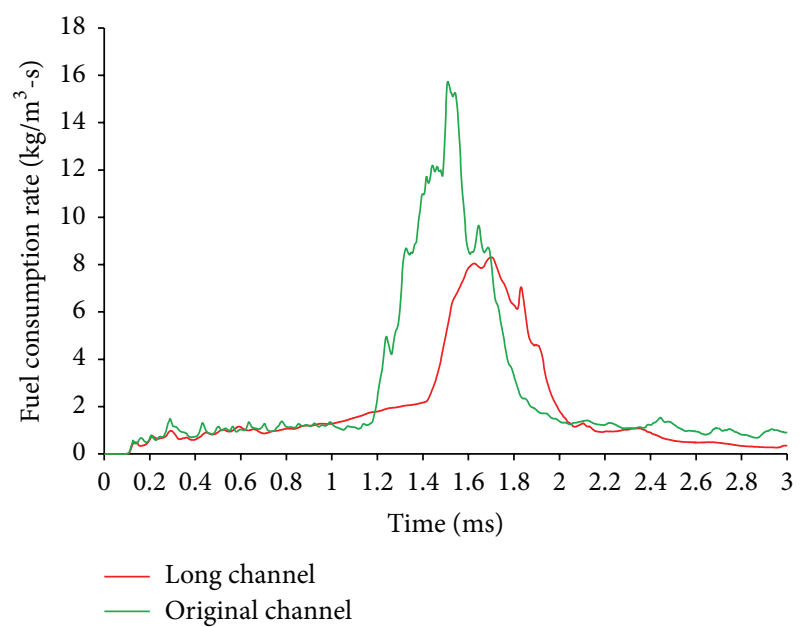

FIGURE 14: Fuel consumption rate for original CVC chamber and extended CVC chamber.

chemical kinetic processes in the jet mixing region. For methane mixture that is initially at room temperature, the heat-releasing processes that involve $\mathrm{CO}$ and $\mathrm{OH}$ appear to be relatively slow compared to the mixing processes. The relatively mixed region undergoes chemical changes that are sensitive to shock heating in the experienced temperature range. These shock events are important in the success of ignition in this region.

The chemistry at the boundary between the mixed region and the unburned region must be considered separately to understand the formation of a propagating flame. The flame behavior is also influenced by shock interaction and by preexisting and generated turbulence. This shock-driven flame acceleration is a separate phenomenon $[37,38]$ beyond the scope of this work.

For propane combustion (Figure 10), the chamberintegrated trends for $\mathrm{C}_{1} / \mathrm{C}_{2}$ species are seen to be rather different from that for methane, but the trends for $\mathrm{OH} / \mathrm{H} / \mathrm{HO}_{2}$ are quite similar. The spatiotemporal distribution of several species was examined for propane or ethylene but was not shown here for brevity. A consequence of the propane reaction pathways is the high production of ethane, $\mathrm{C}_{2} \mathrm{H}_{6}$, with peaks corresponding to the two major shock-flame interactions, while other $\mathrm{C}_{2} / \mathrm{C}_{1}$ species are seen to be consumed. $\mathrm{C}_{2} \mathrm{H}_{6}$ is generated and remains as a stable species for some time in the combustion of propane.

For ethylene combustion, Westbrook et al. [39] reported that $\mathrm{H}$-atom abstraction from ethylene by $\mathrm{OH}$ attack dominated fuel consumption based on well-stirred reactor experiments operating at atmospheric pressure and temperature in the range of 1003 to $1253 \mathrm{~K}$. The initial reaction during the combustion of higher alkane and alkene compounds is dominated by the $\beta$-scission process [40], which leads to the production of ethylene. While a substantial amount of ethylene is oxidized to $\mathrm{C}_{1}$ species and formaldehyde, acetylene may form as a result of pyrolytic reactions of ethylene. For stoichiometric to fuel rich flames, acetylene is the dominant intermediate. 
A pressure-gain constant-volume combustor using hot jet ignition (such as a wave rotor) may be required to start up and operate with various fuels (such as natural gas and jet fuel) at low mixture temperature, more so than combustion engines with mechanical compression. The different behavior of ethylene and propane combustion compared to methane at low initial temperature underlies the need for applying detailed kinetic models to hot jet ignition considering specific fuels and operating temperature range. These are topics of ongoing and future investigations.

3.6. Shock Interaction Timing. The ignition delay in the combustion of mixture in the CVC chamber is dependent on the delay time due to chemical kinetics as well as the delay time due to mixing and jet penetration. The internal gas dynamics of a long closed chamber typically gives rise to the discussed shock wave that reflects and returns to the region of ignition. The chemical ignition delay time may be shortened by shock compression and vorticity deposited in nonuniform density regions.

It is useful to verify that the timing of shock arrival controlled the timing of significant chemical reaction in the jet mixing region. For this, the length of the CVC chamber was increased to 20 inches from original 16 inches, which would delay the reflecting shock return. This case is simulated for the combustion of methane using DRM19, and results are compared with the original geometry. Shock wave reflection for the extended length CVC chamber was seen at time $t=$ $1.0 \mathrm{~ms}$, later than for the original geometry $(t=0.8 \mathrm{~ms})$. Similarly, the deformation of the flame front was seen at about $t=1.8 \mathrm{~ms}$ for extended length CVC chamber, later than $t=1.4 \mathrm{~ms}$ for original geometry. The fuel consumption rates for two cases are presented in Figure 14. The longer CVC chamber causes a delay of approximately $0.2 \mathrm{~ms}$ in the sudden rise of fuel and oxygen consumption rates, but the peak rate is lower. This is attributed to the fact that there has been additional time for mixing, resulting in weaker density gradients and less intensity of stirring by shock-deposited vorticity. Additional fuel reaction during this $0.2 \mathrm{~ms}$ delay is seen to be quite small.

Subsequent flame propagation may also be enhanced by baroclinic vorticity deposition as the driver of the interface deformation produced at different scales [41]. Analytical studies, experiments, and numerical simulations of the classic Richtmyer-Meshkov instability have been reviewed by Rupert [42], Zabusky [43], and Brouillette [44], respectively. The interactions of expansion waves as well as shocks to area increase and amplification of fuel reaction rate has been reported [37, 38, 41, 45]. Shock-flame interaction study is beyond the scope of this work.

\section{Conclusion and Future Work}

Detailed numerical simulations have been performed to investigate the ignition characteristics of a hot jet ignition in a constant-volume combustor, initially containing fuel-air mixtures at room temperature. Detailed chemical kinetic mechanisms have been used to characterize ignition processes for three hydrocarbon stoichiometric mixtures considered in the CVC chamber. Initial reactions of methane are expectedly slow upon jet injection and mixing. The formation of $C_{1} / C_{2}$ intermediate species signifies the breakdown of fuel species but does not necessarily signify that heat release has commenced. The times of sudden increase in oxidation rates and $\mathrm{OH}, \mathrm{H}$, and $\mathrm{HO}_{2}$ production rates for all the three fuel mixtures are seen to be associated with observed reflected shock interaction with the mixed region of injected hot gas and fuel-air mixture. These observations indicate that the effect of propagating waves is important in accelerating combustion by shock compression and accelerated mixing at locations where fuel-air mixture is being entrained by the hot gas jet.

Based on the relative levels of $\mathrm{C}_{2}$ species, it is inferred that the low-temperature and high-temperature reaction pathways of methane combustion are probably both important. The substantial conversion of intermediate species into $\mathrm{CO}_{2}$ takes about $1.5 \mathrm{~ms}$ from the time the intermediate species are first produced significantly, thus complicating the definition of an ignition delay time. Computations indicate that the fuel consumption rate increases significantly due to shockflame interactions, which play a major role in ignition. This has been demonstrated by modeling two cases with different lengths of the CVC chamber. Ignition of the mixture is seen to be delayed by the expected additional time for the initial shock wave to reflect and return to the jet mixing. There are multiple ways in which the combustion rate is accelerated by the shock interaction, including baroclinic vorticity stirring of nonuniform regions within the jet mixing region and shock compression increase in temperatures. For the room-temperature mixtures considered, the temperature increase due to shock compression may be critical. It is expected that, with higher initial mixture temperature that may be representative of practical systems and operating conditions, the shock contribution to faster mixing and flame acceleration may become more important. The experimental and numerical assessment of ignition over a wider range of initial temperature is a needed area of investigation, ideally with fully three-dimensional modeling of the jet mixing process.

\section{Additional Points}

There were no human or animal subjects involved.

\section{Disclosure}

Abdullah Karimi is currently with Southland Industries, Dulles, VA, USA.

\section{Competing Interests}

There are no known competing interests related to the financial support for this work.

\section{Acknowledgments}

This material is based upon work partially supported by the US National Science Foundation under Grant no. CBET1235696. 


\section{References}

[1] E. Toulson, H. J. Schock, and W. P. Attard, "A review of prechamber initiated jet ignition combustion systems," SAE Paper 2010-01-2263, 2010.

[2] W. P. Attard, E. Toulson, A. Huisjen, X. Chen, G. Zhu, and H. Schock, "Spark ignition and pre-chamber turbulent jet ignition combustion visualization," SAE Paper 2012-01-0823, SAE International, 2012.

[3] D. H. Lieberman and J. E. Shepherd, "Detonation initiation by hot turbulent jet for use in pulse detonation engines," in Proceedings of the 38th AIAA/ASME/SAE/ASEE Joint Propulsion Conference and Exhibit, AIAA 2002-3909, Indianapolis, IN, USA, July 2002.

[4] Y. Matsutomi, S. E. Meyer, S. D. Wijeyakulasuriya et al., "Experimental investigation on the wave rotor constant volume combustor," in Proceedings of the 46th AIAA/ASME/SAE/ASEE Joint Propulsion Conference \& Exhibit, AIAA 2010-7042, Nashville, Tenn, USA, July 2010.

[5] P. Akbari and M. R. Nalim, "Review of recent developments in wave rotor combustion technology," Journal of Propulsion \& Power, vol. 25, no. 4, pp. 833-844, 2009.

[6] J. J. Keller, "Pressure wave machine with constant-volume combustion as a superstage for gas turbines," Tech. Rep. CRBT 9020, Asea Brown Boveri, 1990.

[7] I. U. Perera, S. D. Wijeyakulasuriya, and M. R. Nalim, "Hot combustion torch jet ignition delay time for ethylene-air mixtures," in Proceedings of the 49th AIAA Aerospace Sciences Meeting Including the New Horizons Forum and Aerospace Exposition, vol. AIAA 2011-95, Orlando, Fla, USA, January 2011.

[8] U. I. Perera, Experimental investigation into combustion torch jet ignition of methane-air, ethylene-air, and propane-air Mixtures [M.S. thesis], IUPUI, 2010.

[9] H. G. Wolfhard, "The ignition of combustible mixtures by hot gases," Journal of Jet Propulsion, vol. 28, no. 12, pp. 798-804, 1958.

[10] M. Vanpée and H. G. Wolfhard, "Comparison between hot gas ignition and limit flame temperatures," ARS Journal, vol. 29, no. 7, pp. 517-519, 1959.

[11] R. J. Cato and J. M. Kuchta, "Hot gas ignition temperatures of hydrocarbon fuel vapor-air mixtures," Tech. Rep. AD0643518, Bureau of Mines, 1966.

[12] N. N. Smirnov and V. F. Nikitin, "Unsteady-state turbulent diffusive combustion in confined volumes," Combustion and Flame, vol. 111, no. 3, pp. 222-256, 1997.

[13] V. I. Tarzhanov, I. V. Telichko, V. G. Vil'danov et al., "Detonation of propane-air mixtures under injection of hot detonation products," Combustion, Explosion and Shock Waves, vol. 42, no. 3, pp. 336-345, 2006.

[14] F. Mayinger, M. Jordan, A. Eder, I. S. Zaslonko, V. P. Karpov, and S. M. Frolov, "Flame-jet ignition of fuel-air mixtures: experimental findings and modeling," in Proceedings of the 17th International Colloquium on the Dynamics of Explosions and Reactive Systems (ICDERS '99), Heidelberg, Germany, 1999.

[15] M. Bilgin, Stationary and rotating hot jet ignition and flame propagation in a premixed cell [Ph.D. dissertation], Aeronautics and Astronautics Department, University of Washington, Seattle, Wash, USA, 1998.

[16] M. Bilgin, J. J. Keller, and R. E. Breidenthal, "Ignition and flame propagation with rotating hot jets in a simulated wave engine test cell," in Proceedings of the 34th AIAA/ASME/SAE/ASEE Joint Propulsion Conference, AIAA 98-3399, July 1998.
[17] D. Baronia, M. R. Nalim, and P. Akbari, "Numerical study of wave rotor ignition and flame propagation in a single-channel rig," in Proceedings of the 43rd AIAA/ASME/SAE/ASEE Joint Propulsion Conference \& Exhibit, AIAA 2007-5054, Cincinnati, Ohio, USA, July 2007.

[18] A. Karimi, M. Rajagopal, and M. R. Nalim, “Traversing hot-jet ignition in a constant-volume combustor," Journal of Engineering for Gas Turbines and Power, vol. 136, no. 4, Article ID 041506, 2013.

[19] A. Karimi, P. Chinnathambi, M. Rajagopal, and R. Nalim, "Hotjet ignition of hydrocarbons and hydrogen in air: effect of jet chemical activity," in Proceedings of the 49th AIAA/ASME/SAE/ ASEE Joint Propulsion Conference, San Jose, Calif, USA, July 2013.

[20] A. Karimi, P. Chinnathambi, M. Rajagopal, and M. R. Nalim, "Effect of jet composition in hot jet ignition of premixed mixture in a constant volume combustor," in Proceedings of the 8th US National Meeting, Paper-070IC-0334, Combustion Institute, Park City, Utah, USA, May 2013.

[21] G. P. Smith, D. M. Golden, M. Frenklach et al., February 2016, http://www.me.berkeley.edu/gri_mech/.

[22] A. Kazakov and M. Frenklach, February 2016, http://www.me .berkeley.edu/drm/.

[23] Z. Luo, C. S. Yoo, E. S. Richardson, J. H. Chen, C. K. Law, and T. Lu, "Chemical explosive mode analysis for a turbulent lifted ethylene jet flame in highly-heated coflow," Combustion and Flame, vol. 159, no. 1, pp. 265-274, 2012.

[24] UCSD, Chemical-Kinetic Mechanisms for Combustion Applications, San Diego Mechanism, Mechanical and Aerospace Engineering (Combustion Research), University of California at San Diego), February 2016, http://web.eng.ucsd.edu/mae/ groups/combustion/sdmech/sandiego20050615/sandiego20050615 .mec.

[25] CD-adapco, STAR-CCM+ User Guide, Version 5.06.010, CDadapco, Detroit, Mich, USA, 2010.

[26] F. R. Menter, "Two-equation eddy-viscosity turbulence models for engineering applications," AIAA Journal, vol. 32, no. 8, pp. 1598-1605, 1994.

[27] C. Depcik, Open-ended thermodynamic cycle simulation [M.S. thesis], University of Michigan, Ann Arbor, Mich, USA, 2000.

[28] S. Gordon and B. J. McBride, "Computer program for calculation of complex chemical equilibrium compositions and applications," NASA Reference Publication 1311, 1996.

[29] D. B. Spalding, "Mixing and chemical reaction in steady confined turbulent flames," Symposium (International) on Combustion: Thirteenth Symposium (International) on Combustion, vol. 13, no. 1, pp. 649-657, 1971.

[30] B. F. Magnussen and B. H. Hjertager, "On mathematical modeling of turbulent combustion with special emphasis on soot formation and combustion," Symposium (International) on Combustion, vol. 16, no. 1, pp. 719-729, 1977.

[31] D. J. Hautman, F. L. Dryer, K. P. Schug, and I. Glassman, "A multiple-step overall kinetic mechanism for the oxidation of hydrocarbons," Combustion Science and Technology, vol. 25, no. 5-6, pp. 219-235, 1981.

[32] A. Mardani, S. Tabejamaat, and M. Ghamari, "Numerical study of influence of molecular diffusion in the Mild combustion regime," Combustion Theory and Modelling, vol. 14, no. 5, pp. 747-774, 2010.

[33] H. Wang, X. You, A. V. Joshi et al., "USC Mech Version II. High-temperature combustion reaction model of $\mathrm{H} 2 / \mathrm{CO} / \mathrm{C1}$ C4 compounds," 2007, http://ignis.usc.edu/USC_Mech_II.htm. 
[34] D. F. Davidson and R. K. Hanson, "Interpreting shock tube ignition data," International Journal of Chemical Kinetics, vol. 36, no. 9, pp. 510-523, 2004.

[35] S. R. Turns, An Introduction to Combustion, McGraw-Hill, New York, NY, USA, 2nd edition, 2000.

[36] P. Glarborg, J. A. Miller, and R. J. Kee, "Kinetic modeling and sensitivity analysis of nitrogen oxide formation in well-stirred reactors," Combustion and Flame, vol. 65, no. 2, pp. 177-202, 1986.

[37] V. Kilchyk, R. Nalim, and C. Merkle, "Shock and expansion wave-laminar flame interaction," in Proceedings of the 6th International Colloquium on Pulsed and Continuous Detonations, Moscow, Russia, 2008.

[38] V. Kilchyk, R. Nalim, and C. Merkle, "Laminar premixed flame fuel consumption rate modulation by shocks and expansion waves," Combustion and Flame, vol. 158, no. 6, pp. 1140-1148, 2011.

[39] C. Westbrook, M. Thornton, W. Pitz, and P. Maltes, "A Kinetic study of ethylene oxidation in a well stirred reactor," in Proceedings of the 22th Symposium (International) on Combustion, pp. 863-871, Seattle, Wash, USA, August 1988.

[40] I. Glassman, Combustion, Academic Press, Orlando, Fla, USA, 2nd edition, 1987.

[41] V. Kilchyk, Pressure-wave amplification of flame area in wave rotor channels [Ph.D. thesis], Purdue University, West Lafayette, Ind, USA, 2009.

[42] V. Rupert, "Shock-interface interaction: current research on the Richtmyer-Meshkov problem," in Shock Waves: Proceedings of the 18th International Symposium on Shock Waves, Held at Sendai, Japan 21-26 July 1991, pp. 83-94, Springer, Berlin, Germany, 1992.

[43] N. Zabusky, "Vortex paradigm for accelerated inhomogeneous flows: visiometrics for the Rayleigh-Taylor and RichtmyerMeshkov environments," Annual Review Fluid Mechanics, vol. 31, pp. 495-536, 1999.

[44] M. Brouillette, "The Richtmyer-Meshkov instability", in Annual Review of Fluid Mechanics, vol. 34, pp. 445-468, 2002.

[45] V. Kilchyk, R. Nalim, and C. Merkle, "Baroclinic vortex sheet production by shocks and expansion waves," Shock Waves, vol. 20, no. 5, pp. 367-380, 2010. 


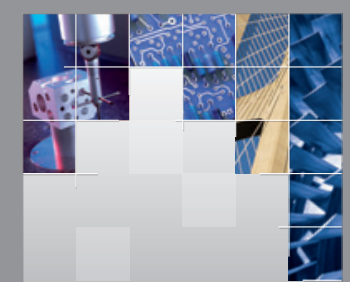

\section{Enfincering}
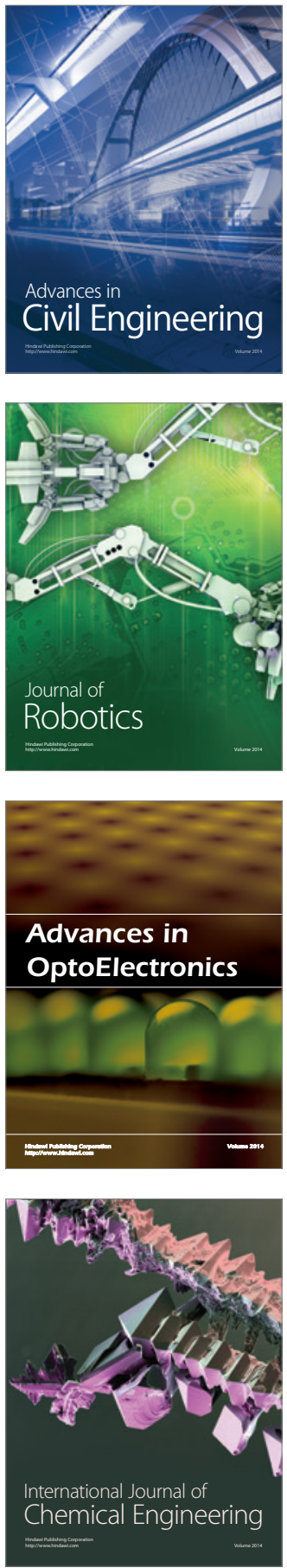

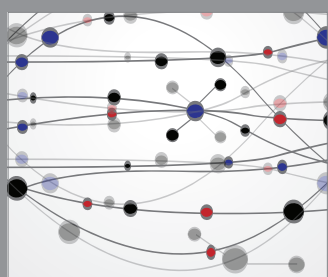

The Scientific World Journal

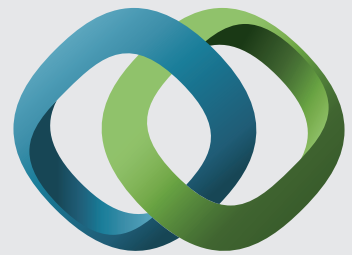

\section{Hindawi}

Submit your manuscripts at

http://www.hindawi.com
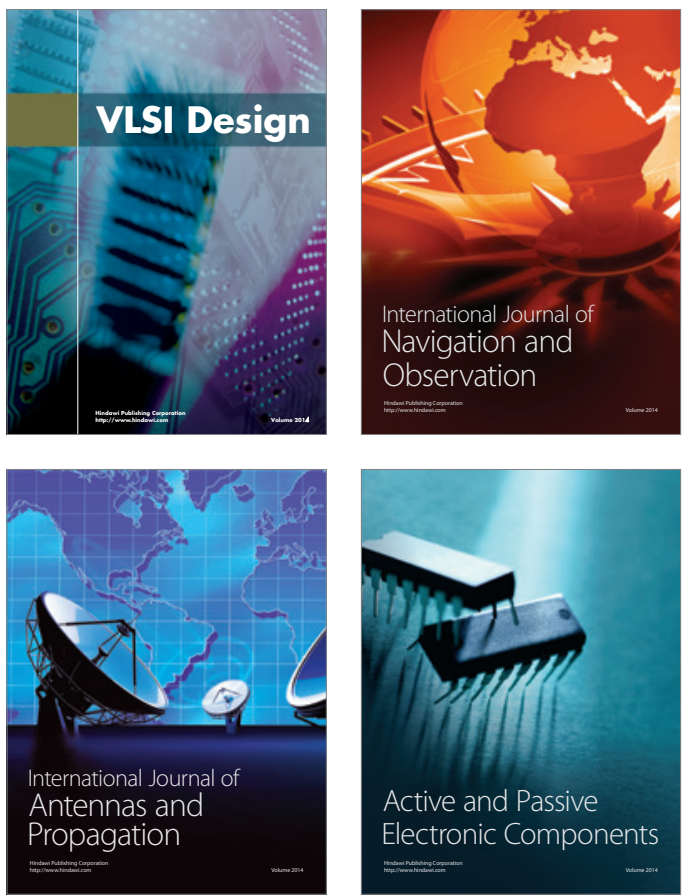
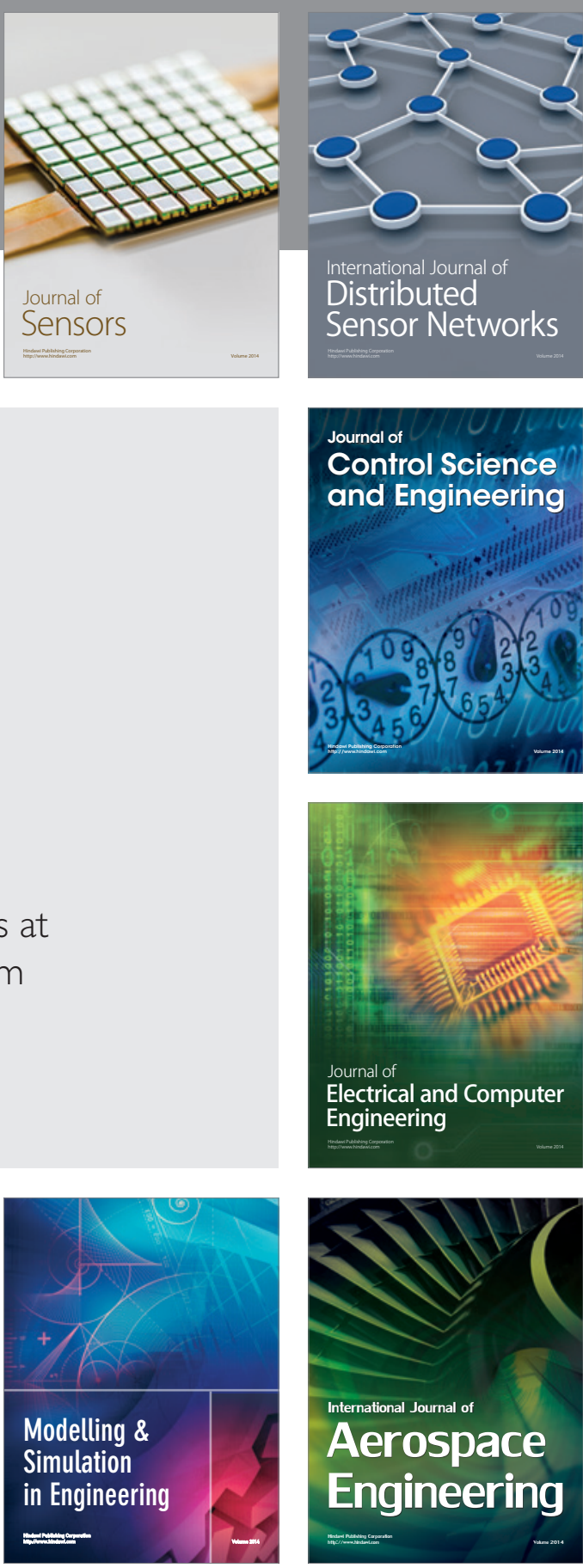

International Journal of

Distributed

Sensor Networks

Journal of

Control Science

and Engineering
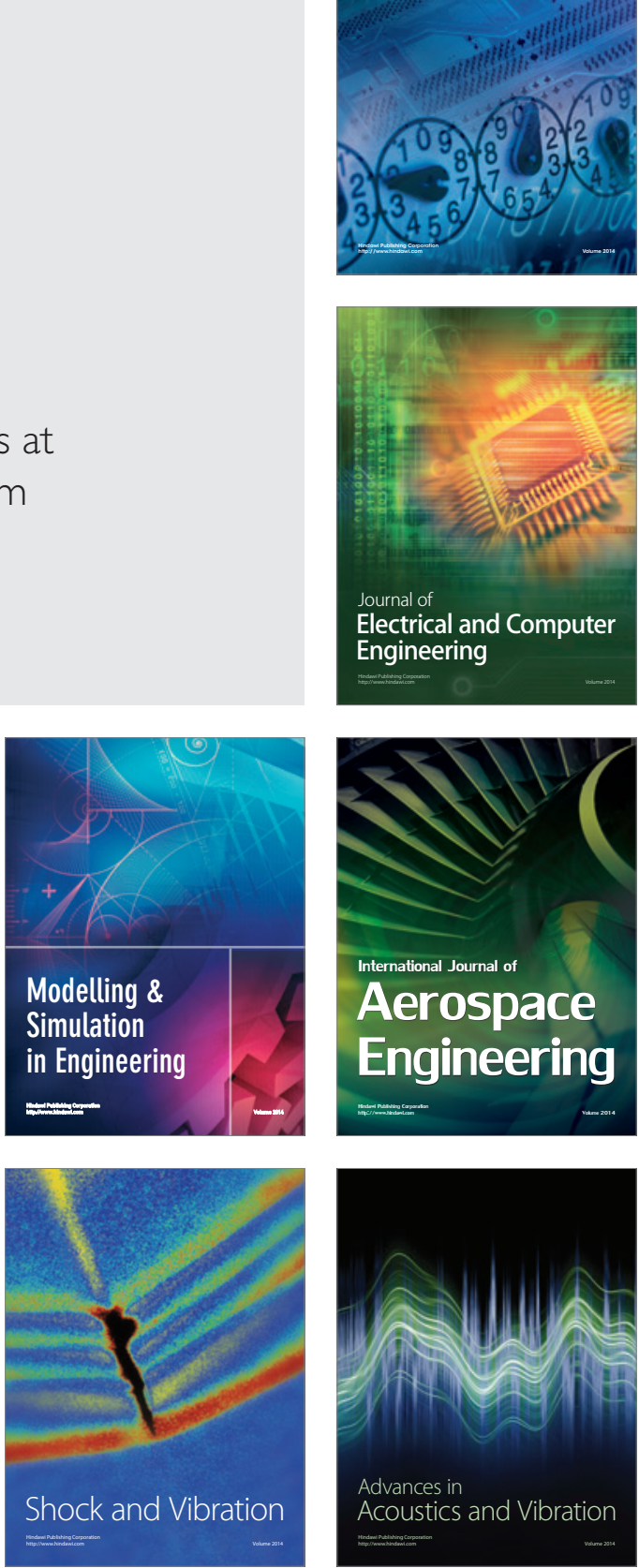